Article

\title{
Embedding Life Design in Future Readiness Efforts to Promote Collective Impact and Economically Sustainable Communities: Conceptual Frameworks and Case Example
}

\author{
Chong Myung Park ${ }^{1}{ }^{\mathbb{D}}$, Angelica Rodriguez ${ }^{2}$, Jazmin Rubi Flete Gomez ${ }^{2}$, Isahiah Erilus ${ }^{2}$, \\ Hayoung Kim Donnelly ${ }^{1}{ }^{\mathbb{D}}$, Yanling Dai ${ }^{1}$, Alexandra Oliver-Davila ${ }^{2}$, Paul Trunfio ${ }^{3}$, Cecilia Nardi ${ }^{4}$, \\ Kimberly A. S. Howard ${ }^{1}$ (D) and V. Scott H. Solberg ${ }^{1, *}$
}

1 BU Center for Future Readiness, Boston University, Boston, MA 02215, USA; cmpark@bu.edu (C.M.P.); hyjkim@bu.edu (H.K.D.); yldai@bu.edu (Y.D.); khoward@bu.edu (K.A.S.H.)

2 Sociedad Latina, Boston, MA 02120, USA; arodriguez@sociedadlatina.org (A.R.); jflete@sociedadlatina.org (J.R.F.G.); ierilus@sociedadlatina.org (I.E.); alex@sociedadlatina.org (A.O.-D.)

3 BU Department of Physics, Boston University, Boston, MA 02215, USA; trunfio@bu.edu

4 BU Government \& Community Affairs, Boston University, Boston, MA 02215, USA; cnardi@bu.edu

* Correspondence: ssolberg@bu.edu

check for updates

Citation: Park, C.M.; Rodriguez, A.; Gomez, J.R.F.; Erilus, I.; Donnelly, H.K.; Dai, Y.; Oliver-Davila, A.; Trunfio, P.; Nardi, C.; Howard, K.A.S.; et al. Embedding Life Design in Future Readiness Efforts to Promote Collective Impact and Economically Sustainable Communities: Conceptual Frameworks and Case Example. Sustainability 2021, 13, 13189. https://doi.org/10.3390/ su132313189

Academic Editor: Adela García-Araci

Received: 8 September 2021

Accepted: 6 November 2021

Published: 29 November 2021

Publisher's Note: MDPI stays neutral with regard to jurisdictional claims in published maps and institutional affiliations.

Copyright: () 2021 by the authors. Licensee MDPI, Basel, Switzerland. This article is an open access article distributed under the terms and conditions of the Creative Commons Attribution (CC BY) license (https:// creativecommons.org/licenses/by/ $4.0 /)$.

\begin{abstract}
This is the first of two sequential papers describing the design and first-year implementation of a collaborative participatory action research effort between Sociedad Latina, a youth serving organization in Boston, Massachusetts, and Boston University. The collaboration aimed to develop and deliver a combined STEM and career development set of lessons for middle school Latinx youth. In the first paper, life design and the U.N. Sustainable Development Goals are described in relation to the rationale and the design of the career development intervention strategy that aims to help middle school youth discover the ways that learning advanced-STEM skills expand future decent work opportunities both within STEM and outside STEM, ultimately leading to an outcome of well-being and sustainable communities. In addition to providing evidence of career development intervention strategies, a qualitative analysis of the collaboration is described. The second paper will discuss two additional frameworks that guided the design and implementation of our work. As an example of translational research, the paper will provide larger national and regional contexts by describing system level career development interventions underway using Bronfenbrenner's bioecological and person-process-context-time frameworks.
\end{abstract}

Keywords: at-risk youth; program design; career readiness; social emotional learning skills

Originally conceived as a career counseling model, life design [1] (Savickas et al., 2009) focuses on helping individuals develop the career adaptability and resilience needed to navigate an increasingly complex and changing world of work [2-4] (Nota et al., 2020; Rossier et al., 2017). While the primary aim of life design is to serve individual clients in a 1:1 counseling setting, life design also proposes an "environment-centered" intervention strategy that strives to support the development of adaptability and resilience by increasing access to quality career services [4] (Rossier et al., 2017). A prime example of this environment-centered approach to life design is school intervention efforts conducted by the Laboratorio di Ricerca e Intervento per l'Orientamento alle Scelte (La. RIOS) at the University of Padova. Their efforts focus on group interventions that are designed to increase inclusion, coping strategies, wellness, and adaptability [5-8] (Ginevra et al., 2017; Nota et al., 2019; Nota et al., 2016; Santilli et al., 2019). Similar to the efforts underway by La.RIOS and aligned with key elements of life design, this paper describes one additional framework and sample intervention activities associated with an environment-centered approach focused on building capacity among community-based organizations and schools to adopt and implement quality career development programs and services, especially for youth living in lower-income households. Because our environment-centered approach 
is predicated upon establishing a collaborative community-based participatory action research effort [9] (Jagers et al., 2019), we have included a qualitative examination of the collaboration quality. Jagers and his colleagues [9] define community-based participatory research as a form of research that focuses on engaging under-served youth and adults in addressing real-world issues in the community through iterative research and action process, which is aligned with the use of qualitative methods.

The primary organizations involved in this collaborative community-based participatory action research effort include the Boston University (BU) Center for Future Readiness (n.d.) and Sociedad Latina (n.d.). Sociedad Latina is a community-based organization that supports the educational attainment and well-being of Boston Latinx youth and their families [10]. In providing Latinx families with quality after-school and summer programs and support, Sociedad Latina has a track record of successfully supporting and mentoring youth in middle school and continuing into post-secondary education. As an after-school and summer program working with the Boston Public Schools District, the collaboration with Boston University involves designing, implementing, and evaluating evidence-based STEM and career learning activities that encourage middle school Latinx youth to consider pursuing pathways to STEM careers. The collaboration with Boston University focuses on supporting their middle school youth as part of Sociedad Latina's STEAM program, incorporating the arts and music into science, technology, engineering, and mathematics learning opportunities. Scientists from the BU Physics Department are redesigning advanced network science curriculum activities referred to as "NetSci for All" [11], and educators from the BU Center for Future Readiness are deploying career development lessons. Both the STEM and career lessons are being adapted collaboratively with Sociedad Latina staff to ensure they are culturally and linguistically relevant for the middle school youth. Below we describe individualized learning plans, high-need, high opportunity youth, and STEM as terms that provide important context to understanding our environment-centered life design effort.

Individualized Learning Plans/My Career and Academic Plan (MyCAP): In an effort to increase access to quality career development programs and services, this intervention is aligned with a national initiative in the U.S. referred to as "college and career readiness". To facilitate college and career readiness, nearly all states have adopted the use of personalized career and academic plan efforts referred to as individualized learning plans [12] (ILPs). As a scope and sequence of activities, ILPs involve classroom/small group activities that develop (a) self-exploration skills that enable youth to identify their talent and skills, (b) career exploration skills enable youth to become aware of how their talent and transferable skills align to high demand occupations, and (c) career management skills that enable youth to identify learning opportunities and postsecondary pathways including access to workbased learning and early college participation that support youth in successfully pursuing their future life goals [13-15]. Research indicates that ILPs show promise in helping students become proactive, resilient, and adaptable, what we refer to as "future ready" [1619]. More specifically, ILPs have shown tremendous promise in motivating youth to select more rigorous course schedules, establish post-secondary goals, and facilitate more substantial connections with family, teachers, and peers [20]. In the U.S., each state uses its own naming convention to refer to ILPs and the Commonwealth of Massachusetts where this effort was implemented, ILPs are referred to as My Career and Academic Plan (MyCAP).

High need, high opportunity youth: This collaboration was derived, in part, from efforts by the BU Center for Future Readiness to design, implement and evaluate career-oriented services that support high need, high opportunity youth populations [19]. Globally, "high need, high opportunity" youth refer to those aged 15-24 who make less than \$2 (USD) per day [21] (est. 500 million) as well as youth and young adults classified as "not in education, employed or training" [22] (NEET; est. 600 million;). We consider these youth "high opportunity" because career service intervention efforts that effectively increase 
their educational attainment and workforce skills also have a tremendous impact on their well-being and economic self-sufficiency.

In the context of this article, high need, high opportunity youth refer to youth attending Boston Public Schools (BPS), including but not limited to BIPOC students (Black, Indigenous, People of Color) and youth with disabilities who are severely at risk for not completing either a two-year or four-year training or degree program six years following high school graduation. In BPS, for example, post-secondary completion rates of students entering the 9th grade in 2008/09 academic year demonstrate severe inequity levels with $40 \%$ of White and $54 \%$ of Asian students completing a two or four-year degree within six years of high school graduation compared with $17 \%$ among Black, $15 \%$ among Latinx, and 5\% among students with disabilities [23]. While it is not surprising that low post-secondary completion rates contribute to Latinx youth facing a precarious economic future, shocking is the degree of income and wealth inequality. The average wealth for Puerto Rican households in Boston is estimated as USD 3000 and Dominican households are estimated as USD 0, while the average wealth among White households in Boston is USD 250,000 [24].

STEM: The aim of this collaborative research project is to co-design, implement, test, and disseminate innovative STEM learning and MyCAP lessons that explore how students emerging STEM skills expand future occupational opportunities. Science Technology, Engineering, and Mathematics (STEM) in this project reflects a new STEM practice that breaks down silos across scientific and technical domains [25]. This new paradigm is in line with a radical shift towards the application of network-based, computational, dataintensive, visualization approaches to solving complex 21st century challenges, such as changing environment, urbanization, and evolving notion of human well-being [26-30]. Therefore, our STEM lessons were designed by using the basic STEM principles, such as water in chemistry, circuits in physics, and viruses in biology, and then these concepts were extended to "network thinking" and its applications in the 21st century.

In sum, the collaboration between Sociedad Latina and Boston University represents an environment-centered life design intervention effort that seeks to address the impact of existing inequities in postsecondary completion rates among high need, high opportunity youth populations. The intervention involves the design and implementation of MyCAP lessons that enable youth to become future-ready (i.e., proactive, resilient, adaptable) by exploring, in part, the ways in which their emerging talent, especially STEM skills, is transferable to a wide range of occupations.

The remaining sections of the paper describe how the UN Sustainable Development Goals guided our effort -8 of the 17 UN Sustainable Development Goals are being used as a framework for describing the rationale of this effort. We also introduce sample MyCAP activities as well as describe the results of a qualitative examination of the progress made in establishing an effective community-based participatory action research collaboration.

\section{Alignment with UN Sustainable Development Goals}

The framework that provides an over-arching rationale for our efforts is the UN Sustainable Development Goals that were adopted internationally to address growing concerns of a global economic collapse [31]. In this section, we propose a logic model (Figure 1) that describes how our environment-centered community intervention efforts are aligned with 8 of the 17 UN Sustainable Development Goals [19,32,33] (SDGs; UN). The logic model situates the primary aim of our effort as increasing the number of high-need, highopportunity youth who access decent, high paying, work (SDG 8). To improve access to decent work, the logic model is predicated upon designing program efforts that increase access to high quality, culturally responsive, and fully inclusive (SDG 10, SDG 5) academic learning and workforce development opportunities (SDG 4). Our MyCAP achieves this goal by focusing on designing group-based learning activities that help youth: (a) identify their emerging transferable skills and talent, (b) learn how their emerging talent and skills align to a wide range of occupational opportunities, and (c) continue engaging in STEM 
learning to expand access to future high wage, high demand occupational opportunities. The long-term success of the effort will be based on the extent to which underrepresented groups such as females (SDG 5), BIPOC youth (SDG 10), and youth with disabilities are able to select among a range of decent-high-wage earning-occupations. By successfully increasing access to decent work, our efforts strive to help communities become more economically competitive (SDG 11) by reducing poverty rates (SDG 1) and hunger (SDG 2) while also improving health and well-being (SDG 3).
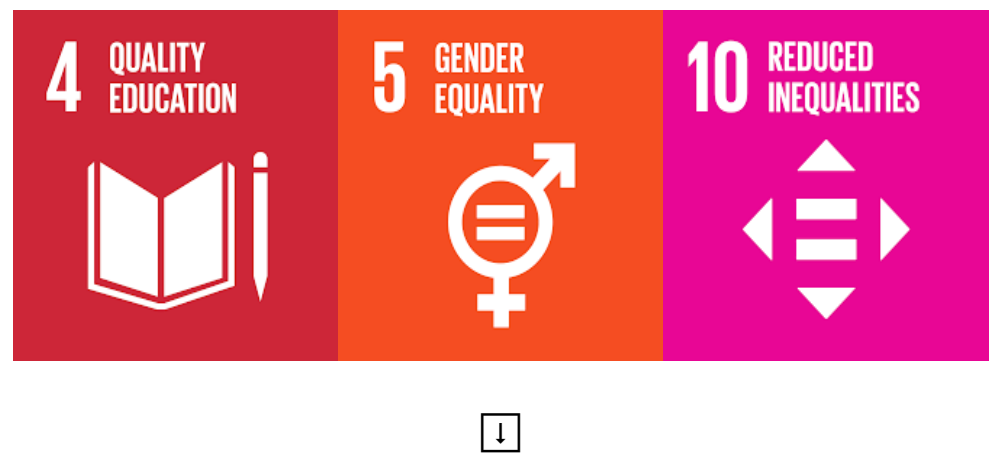

Target Outcome

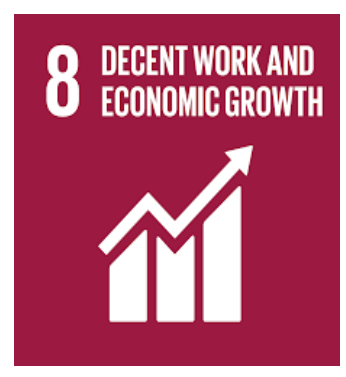

$\square$

Impact

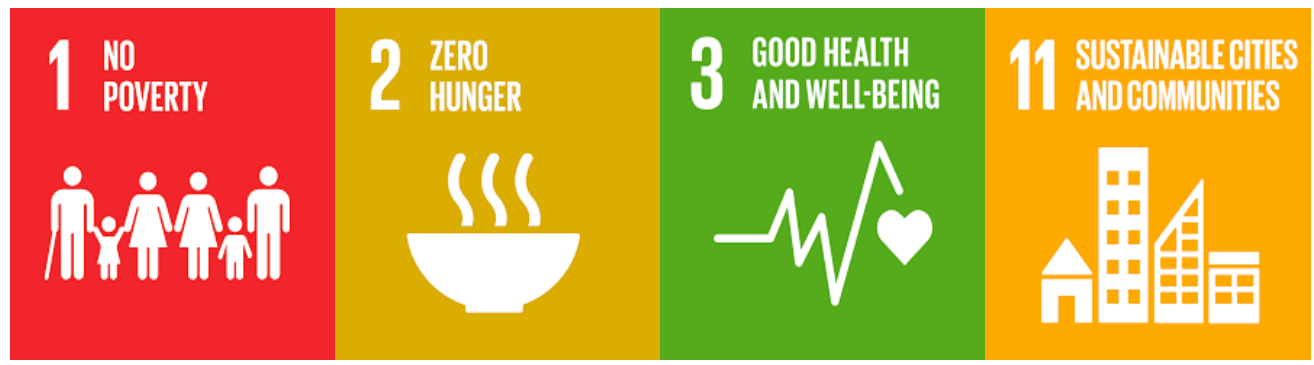

Figure 1. BU Center for Future Readiness SDG logic model. Source: UN, 2017.

\section{Becoming Critically Conscious of Assumptions Underlying Career Service Design}

Life design challenges the traditional career development practice by questioning the use of validated assessments to help clients find the best fit between their personal qualities and occupations that align with those qualities [3]. Our collaborative efforts are consistent with life design's encouragement to use more narrative assessment strategies, move away from using objective measures of interests and personality, and focus on and malleable and evidence-based personal qualities (e.g., self-efficacy, self-determination, motivation, goal setting) that are known to support youth in becoming more proactive, resilient and adaptable $[16,18,19,34]$. 
In addition to challenging the use of objective interest and personality assessments, Sultana [35] goes further by challenging traditional career development assumptions such as internal locus of control, career decision-making based on personal interests that ignore environment and the cultural contexts in which youth are embedded, and individual decision-making that does not take into account the "collective, spiritual, or community connections" that are important identity qualities for many cultures. Similar sentiments regarding the assumptions in the use of interest and vocational assessments have been criticized as treating individuals as commodities designed to be attractive to a capitalist and industrialized world of work that negates many of the values and sources of motivation found in collectivist cultures [36].

A second concern raised by life design scholars is that due to increased awareness of the precarious nature of employment, traditional career counseling's emphasis on helping clients make effective (i.e., the correct) career decisions (i.e., "prescribing" career advice) is not viable in today's world of work [3]. While there are prevailing assumptions that career guidance and decision-making efforts were relevant when the US experienced a period of relatively stable employment [37] (e.g., end of WWI-1970's), historians argue that for individuals from lower income or ethnically diverse backgrounds, the world of work has always been precarious [38]. Blustein and colleagues [39] argue that what has changed in recent years is an erosion in social welfare supports (i.e., health benefits, vacation, retirement accounts, wage increases) due to neoliberalism business practices that emphasize deregulation and open market policies. Henwood [38] argues that the most pressing issues in the world of work are that:

Wages are stagnant or worse, benefits are eroding, and much labor is dull, alienating, pointless, and sometimes dangerous. As a result, many people with typical, full-time jobs have a hard time making ends meet, and most households have little or no savings to fall back on in a crisis.

When considering the design of career related interventions for many high need, high opportunity youth, Sultana [35] points out that contextual constraints such as structural inequities, racism, and gender inequality too often limit access to quality education and job training opportunities and therefore traditional approaches such as the use of objective interest assessments likely narrow self and career exploration [13]. Moreover, Sultana argues that high rates of economic inequality, such as the wealth discrepancies found between Boston Latinx families and White families, impact youth access to quality learning opportunities, resulting in lower rates of youth employment and post-secondary education.

While life design aims to address these inequities using interventions that develop "coping strategies," our collaboration seeks to enable youth to develop the human, technical, and career management skills [40] needed to become future-ready. We define "future-ready" as youth who begin shaping their future learning and life opportunities by becoming proactive, resilient, and adaptable young adults [19].

Using a critical psychology lens, Blustein and his colleagues [39] identify three important considerations in conducting STEM career-related interventions. The first consideration is whether, as a profession, career researchers should be serving business and industry interests by encouraging high need, high opportunity youth to consider STEM careers. The second consideration is that by focusing on STEM careers, career researchers are likely to ignore nonSTEM career interests that could be a better fit for their personality type. The third consideration is whether our efforts should focus on encouraging high need, high opportunity youth to consider STEM careers or intervening with industry to improve work environments that have historically not been welcoming to women and individuals from diverse racial/ethnic backgrounds.

Concerning the first two considerations, one crucial distinction in our implementation is that youth elect to participate in Sociedad Latina's after-school STEAM Team. And our design efforts focus on developing advanced STEM learning skills that strive to expand future access to STEM and nonSTEM occupational opportunities by building youth self-efficacy for engaging in science and thereby supporting future engagement in 
more advanced science coursework. Self-exploration activities help youth identify how the advanced STEM skills align to a broad range of future opportunities and bring awareness of the value of STEM learning skills. We do encourage consideration of STEM occupations as one of three future options as they begin to identify career and life goals. Our rationale for supporting high need, high opportunity youth in considering STEM occupations is based on longitudinal research that determined that they will not consider STEM career options without designed efforts to engage the youth of color in STEM learning and career exploration. As a matter of social justice, we believe high need, high opportunity youth and their families should have a choice in selecting future career and life goals and by not being aware of STEM as a high wage, high demand opportunity or having an opportunity to develop important STEM skills that can serve as the foundational self-efficacy needed to perceive themselves as capable of pursuing a STEM career option, then they will not be in a position to exercise that choice.

With respect to the third consideration, we agree that it is important to intervene at the employer level and intervene in ways that address structural inequities and racism that impact both access to STEM occupations and that push out women and BIPOC individuals out of STEM Within the context of this project, one of the examples of collective impact (see below) is that the MyCAP lessons are being used by Boston Public Schools as part of a Transformative Mentoring program where significant attention is paid to helping adult mentors first become critically conscious of how structural inequities and racism impacts their interactions with youth. The BU Center for Future Readiness was asked to help in the design and implementation of this effort which will allow these mentor-focused development activities to be incorporated into other MyCAP professional development efforts. At a national level, the BU Center for Future Readiness helped establish a national Coalition for Career Development Center, which is industry-led and makes STEM equity a primary concern.

In sum, our collaboration design efforts aim to address structural inequities and prevalent racism that prevents many Latinx youth in Boston from gaining access to quality learning and workforce development opportunities. We intend to increase access to quality STEM learning and career services and support Sociedad Latina's current efforts to support educational attainment and future readiness by supporting youth in charting a range of occupational pathways that include possessing the workforce skills needed to directly enter decent, high wage/high demand work opportunities such as STEM occupations after high school as well as to identify "on-ramps" into training, two-year and four-year programs that align to their future career and life goals.

\section{Sample MyCAP Activities}

In this section, we provide information on the lesson products that resulted from our collaborative research. MyCAP activities were originally designed to support the BPS districtwide high school implementation [41]. Sociedad Latina staff, with support of the BU Center for Future Readiness, redesigned these lessons to make them more culturally and linguistically accessible for Latinx middle school youth [10]. This section will focus on two of three Who Am I lessons that develop self-exploration and career exploration skills. Who Am I was modified from a lesson originally developed by Perry and his colleagues as part of their "Making My Future Work" lesson guide [42,43]. The Who Am I lesson facilitates a 45-min group conversation about one's skills and talent and then explores how they align to a wide range of occupations. One key modification to the Who Am I lesson is that the personal qualities youth explore were drawn from a list of human skills (i.e., advanced social emotional learning skills) that employers have identified as in high demand [44]. Given this past year's need to create remote learning, the Who Am I lesson consists of two interactive online activities using Microsoft PowerPoint as well as different add-on features such as Nearpod [45] (n.d.). While originally developed by EdVestors [11] (n.d.) for use with BPS high schools, the lessons were modified by Sociedad Latina (n.d.) to be relevant for middle school youth, and a third modification was made by Harvard 
University's National Center for Rural Education Research Networks [46]. Sample slides are presented in Appendix A.

What is noteworthy about the Who Am I slides is the emphasis on using a narrative assessment strategy that enables youth to identify their current and emerging "human" skills. The conversation is designed to help youth recognize that these human qualities are advanced social emotional learning skills that represent their emerging talent and skills that are in high demand in the world of work. The second activity develops career exploration skills using $\mathrm{O}^{*}$ NET's advanced skills search feature. This feature involves clicking on a list of workforce skills the individual perceives themselves as possessing or developing. Based on those selected, $\mathrm{O}^{*}$ NET generates a list of occupations that align to those skills. While we do support youth to identify the technical skills they are learning as part of the advanced STEM lessons they learned, by generating a wide range of both STEM and nonSTEM occupations, $\mathrm{O}^{*}$ NET helps youth and the adults facilitating the activities to become aware of the relevance and value of STEM learning. Additional MyCAP lessons develop career exploration skills by helping youth compare two occupations with respect to skills, activities, and labor market information (i.e., salary, job opening projections). As noted above, the focus of these activities is to develop self-exploration and career exploration skills and support youth in establishing future goals (emphasis on plural). And, in reference to the important considerations raised by Blustein and his colleagues, while the context of the effort involves STEM learning, the goal is to empower youth with the skills needed to define their own range of future opportunities and identify the learning opportunities that support them in pursuing those opportunities.

\section{Collective Impact}

According to Flood, Minkler, Lavery, Estrada, and Falbe [47], the conditions necessary to achieve collective impact, that is to facilitate large scale adoption of the STEM and MyCAP lessons, include: (a) establishing a common agenda, (b) mutually reinforcing activities, (c) continuing communication, (d) establishing a system of organization, and (e) having a standard measurement for both implementation quality and outcomes. With respect to "establishing a common agenda" and "mutually reinforcing activities," BPS' engagement in MyCAP was facilitated by a number of meetings with district officials well prior to the current project as well as district officials participating in a three-workshop series offered by Massachusetts DESE [48]. As part of their focus on supporting career pathways, EdVestors staff also participated in the MyCAP workshops and supported the BU Center for Future Readiness to provide coaching support for Boston Public High Schools. It was in this context that Boston Public Schools requested, and EdVestors supported, the development of specific lessons that would encourage schools to adopt MyCAP. In reading about the nature and value of MyCAP [13], district officials discovered that the student-driven focus on empowering youth to develop the skills needed to become proactive, resilient, and adaptable adults was in line with their recently adopted College, Career, and Life Ready framework $[49,50]$.

Efforts to "continue communication" and "establish a system of organization" are emerging. Remote access enabled more frequent and efficient engagement to discuss planning and provide professional development. And, in preparation for an expanding engagement in MyCAP in BPS in collaboration with Sociedad Latina and Boston University, it is clear that a system of organization is needed to coordinate lesson development and diffuse innovative ideas and practices across the district. Sociedad Latina's efforts will parallel and contribute to this development and diffusion by adding MyCAP lessons into their high school support programs. At the end of the Spring term, the lessons were evaluated by student interns, and their feedback along with a larger community of practice discussion with educators and students throughout Boston has resulted in a set of lesson design recommendations that will be used to guide future lesson development [51]. A separate organizing team is being established whereby relevant departments within BPS and Massachusetts DESE in collaboration with Sociedad Latina and the BU Center for 
Future Readiness will have an assigned full-time coordinator to track lesson development and ensure that all parties, including educators and youth-serving organizations are able to access the lessons as well as professional development opportunities.

Achieving a standard measurement of implementation and outcomes is a work in progress that will be undertaken as part of the new organizational structure that is being launched. Each separate implementation of MyCAP within BPS and Sociedad Latina has measurement efforts underway, and the plan is to share these efforts in order to establish a common set of measures that can be used across the different efforts.

\section{Qualitative Investigation of the Project Collaboration}

During the initial design of this project, we proposed a scientific examination of this capacity building using qualitative methods to better understand the culture and complexities that facilitate and challenge the creation of effective community-based collaborations [52]. Collaborative research that is interdisciplinary or transdisciplinary is common in science and medicine [53-55]. Bansal et al. [53] provide the core elements of an effective collaboration that involves coordination between institutions, organizations, and/or communities: (a) collaboration that invites open communications for system change; (b) identification of stakeholders and their engagement in providing feedback; (c) clear roles and responsibilities, and (d) respect for different organizational cultures and professional environment. Using modified grounded theory, some of these elements will be explored as they emerge as major themes identified based on two data sources, one-on-one interviews and weekly meeting observations.

\subsection{Participants}

The qualitative analysis is based on field notes from weekly meetings among staff members that include Sociedad Latina's STEAM Pathway Manager and two STEAM Program Coordinators and the Boston University PI, co-PIs, Project Manager, two graduate research assistants, and the university's Director of Community Relations. In addition, two staff from Sociedad Latina and two from Boston University were interviewed to better understand the complex culture of the collaboration. These four participants were selected because they have been part of the project since the grant proposal and contributed to the establishment of the collaborative culture.

\subsection{Procedure}

Two staff members from Sociedad Latina were interviewed in Fall 2020, and two staff members from Boston University were interviewed in the Spring 2021, respectively. Each interview lasted about $30 \mathrm{~min}$ via Zoom and was recorded and transcribed. The interviews were semi-structured with the flexibility of focusing on the themes that seemed more meaningful to each participant. Interview questions include: (a) How was your overall collaboration experience (e.g., impressions, takeaways)? (b) What did you like the most/least about collaboration? (c) What were the challenges that you faced due to the unforeseen changes caused by COVID-19? (d) What were the successes you have achieved in this new collaborative environment? (e) How could this collaboration be improved?

Since the design phase of the first summer programming in 2020, the team has had three meetings each week, around the topics of curriculum, evaluation, and the checkin meetings with the whole group, reaching an approximate number of 150 meetings, in total. The Project Manager has maintained the meeting notes, and these were reviewed for the data triangulation purpose, to verify the information that was discussed during the interviews and identify additional information that can support the statements of the interviewees. Member checking was done during the writing process.

\subsection{Plan for Data Analysis}

As a qualitative analytic strategy, a modified grounded theory approach was used to identify emerging themes. The interview transcripts were thematically analyzed using the 
six steps of Braun and Clarke [56]: (a) become familiar with the data, (b) generate initial codes, (c) search for themes, (d) review themes, (e) define themes, and (f) write-up. The field notes from the weekly meetings were reviewed as an additional data source that helps develop a comprehensive understanding of the collaborative culture $[57,58]$. The analytic results were shared with the project members during the write-up process to verify whether the findings reflect their thoughts and experiences appropriately. Grounded in the voice of the staff members of this collaboration [59], it was possible to identify two emerging qualities that reveal who we are as collaborators, respect and trust. Two additional themes will be discussed - challenges and successes - that we believe provide further information on what contributed to the culture of our collaboration.

\subsection{Findings}

Four themes emerged from the analysis of field notes and interviews: mutual respect, trust, managing through COVID-19, and discovering positive outcomes of remote learning.

Respect for Each Other's Expertise. "Community organizations have bad experiences because the university comes in and it's an experiment for the university but it's real for those people "(Katie, BU staff). We often underestimate the value of experience that our community organizations have established over many years. The negative connotation that university faculty carries when coming into a community-based organization is real and based on the misbelief that academic knowledge is "better" than experience. Sofia, a Sociedad Latina staff, recalled that the BU team came in at a time when they were struggling to show concrete evidence of their effectiveness and relying on the anecdotes of their high school graduation and college entrance rates. Unlike the common misconception, the BU faculty entered with great appreciation and respect for the expertise of Sociedad Latina: "They (Sociedad Latina) are clearly good at what they do" (BU staff). In turn, Sociedad Latina recognized that the faculty were coming in with "a good understanding of youth development, curriculum design and evaluation" (Sociedad Latina staff). For a collaboration to be meaningful and productive, each team member has to have their area of expertise-knowledge and/or experience-and others appreciate how each member of the collaboration is contributing to the project and making things better as a team. In our case, verbal appreciations were repeated over time at our internal meetings, external meetings with educators, workshops, and conferences. Whether intentional or unintentional, verbally expressing respect for others in a consistent manner elevated our mutual respect. This in turn allowed our weekly meetings and conversations to be positive and constructive, leading to increased productivity despite the challenges caused by COVID-19.

Trust Building and Togetherness. It is so true that it could have been difficult for us to build this level of trust if we had to build a new relationship during the pandemic. Luckily, our collaboration goes far before COVID-19 hit us all when we were writing the funding applications together. We were able to meet in person back then and make small talk before and after the meetings about the weather, families, updates in the district, and simply getting to know more about each other. Based on the "organic relationship" that happened a few minutes before and after the meetings, our continuing conversations led us to believe that we have a common goal of supporting the youth and families that otherwise will not have access to quality STEM learning and career development opportunities. We felt positive energy growing in our conversations and were convinced that we could create a synergetic impact together. The Zoom setting, however, often provides us limited opportunity to "get to know each other better" and "feel the energy" because we do not physically share space. What kept us going was the culture of our collaboration rooted upon mutual respect and the consistency that no matter what setting we are at, we check in on each other, listen to their concerns, and ask them to reflect and provide feedback: "There is no question we've built a level of trust with them. And I think that goes both ways" (BU staff). "You don't have anything unless you have trust; I think that's the foundation" (Sociedad Latina staff). 
COVID-19 Challenges. Going through tough times together often cements the relationship. The pandemic helped us understand the feelings of others, think as a community, and recognize each other as partners who navigate the difficulties together. The challenges commonly identified across interview transcripts and meeting observation notes tie into our rapid transition to remote learning that nobody was prepared for. First, it was difficult for us to have a concrete understanding of the target population, especially for those who never worked with middle school students before, as we were unable to meet students in person before our summer pilot began. Designing lessons while considering their attention span in a remote setting was challenging as it is an area of inquiry that has not been explored much. Second, we were unable to observe the students' body language during the lessons, how they engage with their peers and their reaction to the lesson activities. The feedback forms and survey results were often limited in showing the full spectrum of student experiences. Third, we were unable to sit around the table and use our full capacity to brainstorm and problem-solve. Our original intentions were to alternate between meeting in person with Sociedad Latina staff on campus and meeting in their building; We could have had students tour the campus and engage in campus learning activities that would supplement the curriculum. These challenges we experienced in managing within a remote learning environment taught us many lessons. We learned to take frequent breaks and have "fun times" on Zoom. We discovered new interactive online techniques and strategies to engage with students and understand their experiences. Most importantly, these challenges gave us an opportunity to reflect on our interactions with youth and their families and understand what is happening at home that affects students' engagement in school and in the program.

Engaging in activities using Zoom also allowed BU staff to participate in Sociedad Latina celebrations and music festivals. These moments offered an opportunity for "chat" shout-outs to staff and youth, laughter, and the opportunity to witness the creative and musical talent of the staff and youth. During the celebration events that occur three times per year (end of summer and end of each academic term), we also witnessed how youth summarized their experiences in the program, and their honesty and voice were always moving and affirming.

Glass Half Full-Bright Side of the Crisis. Ironically, one of the successes we believe we made together was managing the challenge of ensuring access during remote learning. The online setting allowed us to reach more youth for snow days and more parents with little children or who work at night to participate in the orientation and parent meetings. It was also an opportunity for them to use Zoom and learn how to use other technologies, which increased their capacity to get engaged in their child/ren's education. Our interactions with the youth also increased because we did not have to arrange time physically to make this happen. The flexibility of Sociedad Latina allowed us to visit on Zoom more frequently to observe or just hang out to see what is happening during the online lessons. We believe this also reduced the psychological distance the youth might have felt about the university and faculty and helped them realize that the universities are accessible, and role models are within reach.

\section{Discussion}

The themes identified from the interviews and field notes are consistent with some of the conditions described by Flood and her colleagues [47] as necessary to maximize impact. It was believed that the process of getting to know each other, the informal conversations we had before and after each meeting, and the genuine interest in each other as a person, which we called "organic relationships", allowed us to build mutual trust. This in turn strengthened our understanding of each other's background and perspectives and enabled us to "establish a common agenda". Another condition of collective impact found consistent with the culture of our collaboration is our effort to "continue communication". With more than 150 weekly meetings conducted during the first year, the engagement of project members and outside experts in different stages of the project, from initiation to 
planning to execution to monitoring was substantial. The amount of engagement was facilitated using remote access platforms that increased accessibility, frequent communications, and inclusivity of junior staff members. "Establishing a system of organization" and "having a standard measurement for both implementation quality and outcomes" are the conditions that certainly exist in our collaborative work but are in development and not reflected in the first-year data sources reviewed for this paper.

The themes identified are also aligned with the four core elements of an effective collaboration reported by Bansal et al. [53]. As described by the two interviewees, Boston University staff respect the experience and expertise of Sociedad Latina it has as a communitybased youth-serving organization. Sociedad Latina staff in turn respect the knowledge and expertise the faculty and researcher bring in as to lesson design and evaluation. Other elements of effective collaboration are reflected throughout our Year 1 practice. First, stakeholders from regional, state, and national levels are invited to our webinars and meetings and asked to provide feedback on our accomplishments and challenges. Second, our collaborative research constantly seeks out feedback from various stakeholders and reflects their ideas and suggestions in the next round of lesson iterations. Third, we created a project management system that allows us to clarify our roles and responsibilities and asks team members to report on what they are working on, what is accomplished each week, and what the next steps are.

"Every word an opportunity, every word a responsibility, every word another chance" [60] (p. 76).

As we are wrapping up the first year, this qualitative review of our first-year collaboration demands a new, innovative way of evaluating collaborations between a communitybased organization and a higher education institution that work together to serve our youth to become future-ready. While such collaboration can improve the adoption and implementation of innovative practices, little is known about establishing positive interdisciplinary, cross-organizational collaborations in social science and what is needed to lead such collaboration to success, mainly due to their complexities and the uniqueness of each project [61]. The identification of themes was one of the first steps that helped us understand our process, and more work is needed to have a deeper understanding of the social and cultural patterns of this collaborative work. The results of this qualitative study of the first year of the program are also meaningful in that it provides an opportunity to consider the future of this collaboration. Our team asks: "What have we learned?"; "What can we do better?"; and "what are we aspiring to do?" It will be exciting to continue our qualitative exploration around what we will be able to add to the culture of our collaboration and have us move up to the next level of collaborative research with increased, collective impact.

\section{Summary}

This is the first of two sequential papers describing the rationale and the process of designing a community-based participatory action research effort between a communitybased organization offering after-school and summer STEM programs-Sociedad Latinaand Boston University and share sample activities with a wide audience. The paper provides a conceptual understanding of our collaborative research using two frameworks. The collaborative effort offers an example of life design's "environment-centered" approach [4] to career development that focuses on supporting middle school Latinx youth in developing self-exploration and career exploration skills needed to enter high school with articulated academic and life goals. A number of U.N. Sustainability Goals were used as a logic model to frame the effort in terms of supporting future access to "decent work" opportunities (UN SDG 8) as a means for reducing poverty (SDG 1) and hunger (SDG 2), improving health and well-being (SDG 3) and ultimately improving the economic competitiveness of the community (SDG 11). In addition to offering examples of lessons and collective impact into the broader Boston Public Schools, a qualitative analysis of the collaboration was used to describe the nature and quality of the community-based participatory action research collaboration. 
Author Contributions: Conceptualization, A.O.-D., P.T., C.N., K.A.S.H. and V.S.H.S.; methodology, C.M.P., K.A.S.H. and V.S.H.S.; software, C.M.P., A.R., J.R.F.G. and I.E.; validation, C.M.P. and V.S.H.S.; formal analysis, C.M.P., H.K.D. and Y.D.; investigation, C.M.P., H.K.D. and Y.D.; resources, A.O.-D., P.T., C.N., K.A.S.H. and V.S.H.S.; data curation, C.M.P. and A.R.; writing-original draft preparation, C.M.P. and V.S.H.S.; writing-review and editing, P.T., K.A.S.H., V.S.H.S.; visualization, A.R. and J.R.F.G.; supervision, A.O.-D., K.A.S.H. and V.S.H.S.; project administration, C.M.P. and A.R.; funding acquisition, A.O.-D., P.T., K.A.S.H. and V.S.H.S. All authors have read and agreed to the published version of the manuscript.

Funding: This research was funded by the National Science Foundation grant number 1949526. And The APC was funded by the National Science Foundation.

Institutional Review Board Statement: The study was conducted according to the guidelines of the Declaration of Helsinki, and approved by the Institutional Review Board (or Ethics Committee) of Boston University (protocol code 5454X, 20 January 2021).

Informed Consent Statement: As an exempt study, consent information was shared with the participants prior to the interview, and the participants had an opportunity to ask questions before providing verbal consent.

Data Availability Statement: The study did not report any data relevant to this paper.

Conflicts of Interest: The authors declare no conflict of interest.

\section{Appendix A}
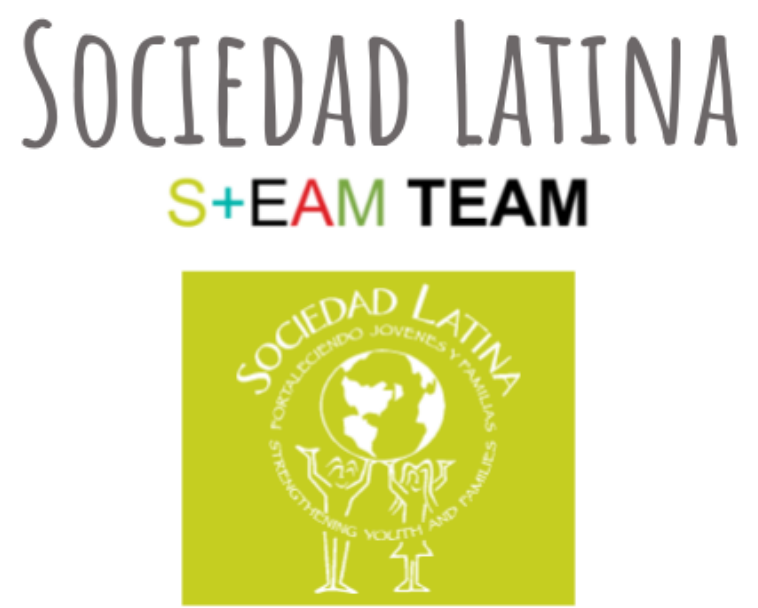

\section{Connecting Skills to Careers Conectando habilidades a carreras}

Figure A1. Sample PowerPoint slide of the Who Am I activities: Connecting Skills to Careers. 


\section{TODAY'S ACTIVITY! LA ACTiVidad de HOY!}

This activity will help you: Esta actividad de ayudará a:

- Describe what makes you unique - Describir lo que te hace único

- Find adjectives that describe yourself that may relate to future career aspirations

- Encontrar adjetivos que te describen a ti mismo que se relacionan a tus aspiraciones de carrera

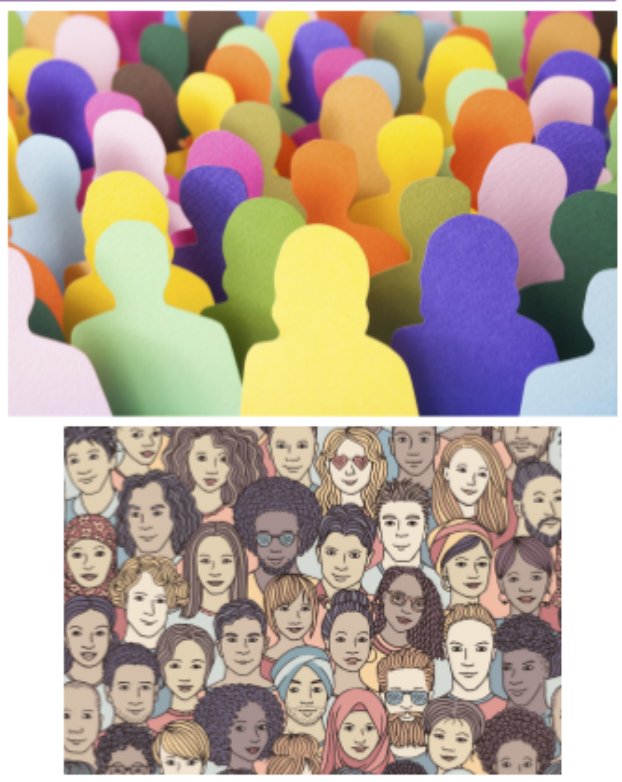

Figure A2. Sample PowerPoint slide of the Who Am I activities: Lesson Objectives.

\section{Drag \& Drop the Talents Or Skills that Best Describe YOU}

For this activity, there are 5 categories that relate to career skills to consider

- Positive Impact

- Communication

- Listening Skills

- Dependability

- Organizational Skills

\section{Important \\ There may be additional talents and skills that you have that may not fall into these areas. Those are still important! For this lesson, we are looking at a subset of skills that are needed in a variety of careers.}

As you complete the activity you can move words that describe you now and words that describe skills you are working on

Figure A3. Sample PowerPoint slide of the Who Am I activities: 5 skill categories to consider. 


\section{Drag \& Drop the Talents or Skills that Best Describe You}

For this first part of the activity, there are 6 categories that relate to career skills to consider:

- Communication

- Collaboration

- Creativity

- Adaptability

- Curiosity

- Interpersonal

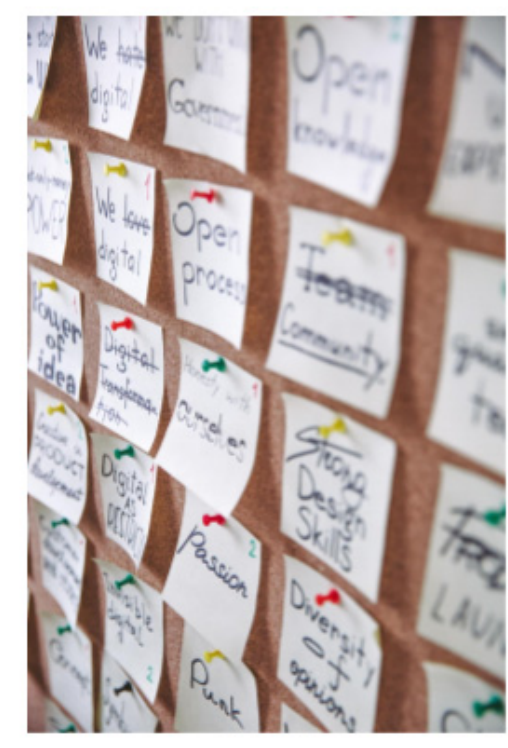

There may be additional talents and skills that you have that may not fall into these areas. Those are still important! For this lesson, we are looking at a subset of skills that are needed in a variety of careers.

As you complete the activity you can move words that describe you now and words that describe skills you are working on.

Figure A4. Sample PowerPoint slide of the Who Am I activities: 6 skill categories to consider.

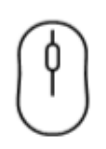

\section{What are your communication skills?}

Drag the circles into the box that describes you.
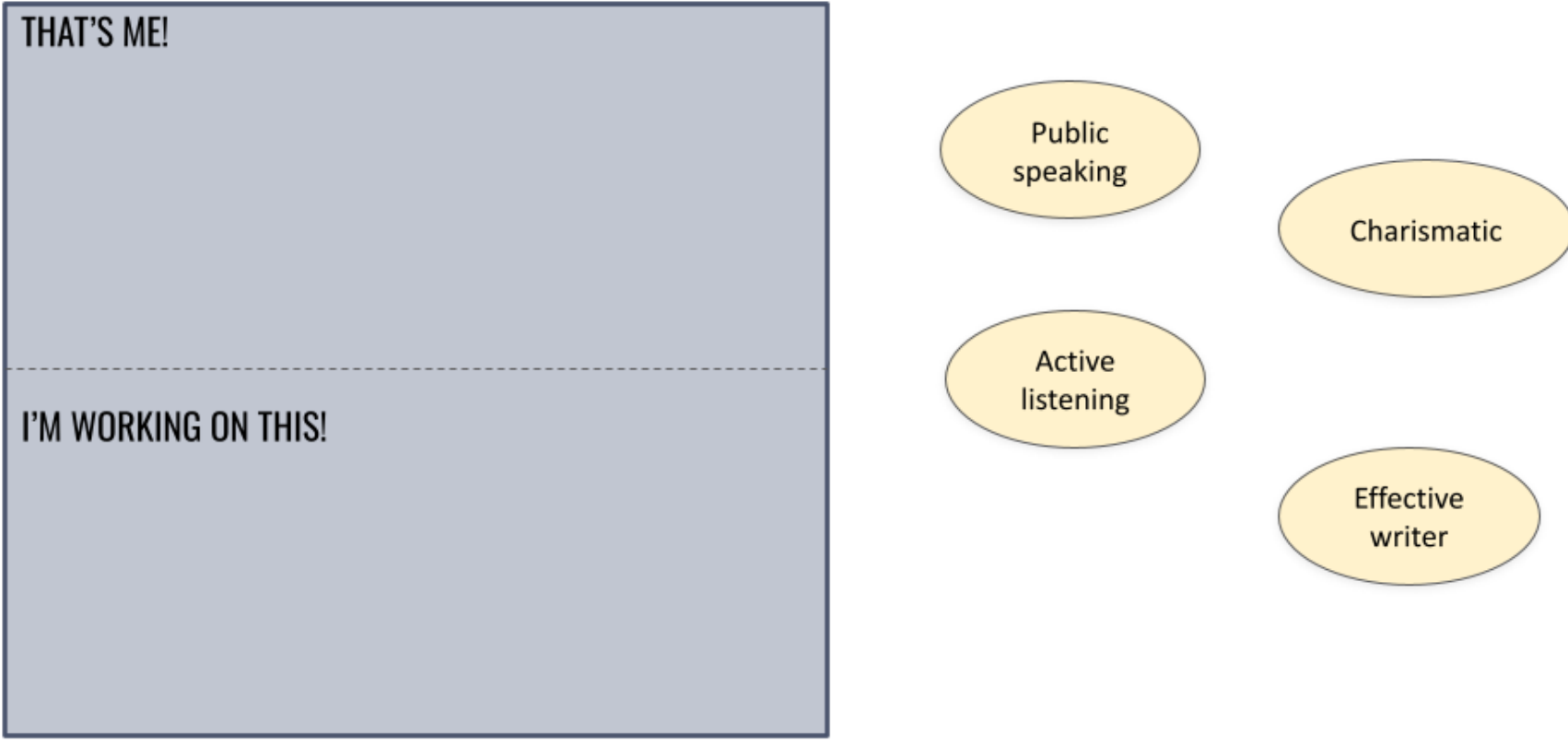

Figure A5. Sample PowerPoint slide of the Who Am I activities: communication skills. 


\section{Reflection \#1: Write your responses in the boxes below}

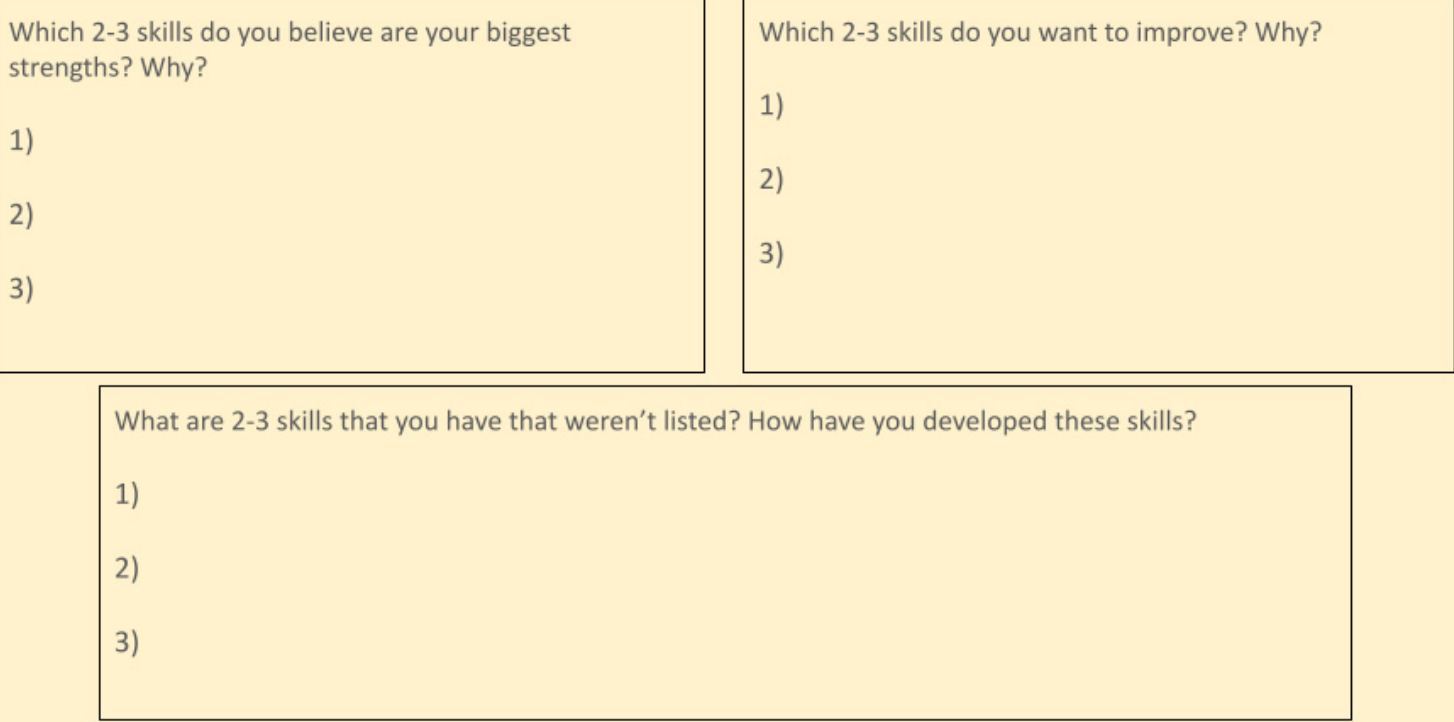

Figure A6. Sample PowerPoint slide of the Who Am I activities: reflection notes.

\section{References}

1. Savickas, M.L.; Nota, L.; Rossier, J.; Dauwalder, J.-P.; Duarte, M.E.; Guichard, J.; Soresi, S.; Van Esbroeck, R.; van Vianen, A. Life designing: A paradigm for career construction in the 21st century. J. Vocat. Behav. 2009, 75, 239-250. [CrossRef]

2. Di Maggio, I.; Ginevra, M.C.; Santilli, S.; Nota, L.; Soresi, S. The Role of Career Adaptability, the Tendency to Consider Systemic Challenges to Attain a Sustainable Development, and Hope to Improve Investments in Higher Education. Front. Psychol. 2020, 11, 1926. [CrossRef] [PubMed]

3. Nota, L.; Soresi, S.; Di Maggio, I.; Santilli, S.; Ginevra, M.C. Sustainable Development, Career Counselling and Career Education; Sustainable Development Goal Series; Springer: Berlin/Heidelberg, Germany, 2020.

4. Rossier, J.; Ginevra, M.C.; Bollmann, G.; Nota, L. The Importance of Career Adaptability, Career Resilience, and Employability in Designing a Successful Life. In Psychology of Career Adaptability, Employability and Resilience; Maree, K., Ed.; Springer: Cham, Switzerland, 2017. [CrossRef]

5. Ginevra, M.C.; Di Maggio, I.; Nota, L.; Soresi, S. Stimulating resources to cope with challenging times and new realities: Effectiveness of a career intervention. Int. J. Educ. Vocat. Guid. 2016, 17, 77-96. [CrossRef]

6. Nota, L.; Ginevra, M.C.; Soresi, S. School inclusion of children with intellectual disability: An intervention program. J. Intellect. Dev. Disabil. 2018, 44, 439-446. [CrossRef]

7. Nota, L.; Santilli, S.; Soresi, S. A Life-Design-Based Online Career Intervention for Early Adolescents: Description and Initial Analysis. Career Dev. Q. 2016, 64, 4-19. [CrossRef]

8. Santilli, S.; Nota, L.; Hartung, P.J. Efficacy of a group career construction intervention with early adolescent youth. J. Vocat. Behav. 2019, 111, 49-58. [CrossRef]

9. Jagers, R.J.; Rivas-Drake, D.; Williams, B. Transformative Social and Emotional Learning (SEL): Toward SEL in Service of Educational Equity and Excellence. Educ. Psychol. 2019, 54, 162-184. [CrossRef]

10. Sociedad Latina. Sociedad Latina: Creating the Next Generation of Latino Leaders. Available online: https: / / www.sociedadlatina. org/ (accessed on 5 July 2021).

11. Cramer, C.; Sheetz, L.; Sayama, H.; Trunfio, P.; Stanley, H.E.; Uzzo, S.M. NetSci High: Bringing Network Science Research to High Schools. Stud. Comput. Intell. Complex Netw. 2015, 597, 209-218. [CrossRef]

12. Office of Disability Employment Policy (ODEP). Individualized Learning Plan. U.S. Department of Labor. Available online: https: //www.dol.gov/agencies/odep/program-areas/individuals/youth/individualized-learning-plan (accessed on 25 July 2021).

13. Solberg, V.S. Making School Relevant with Individualized Learning Plans: Helping Students Create Their Own Career and Life Goals; Harvard Education Press: Cambridge, MA, USA, 2019.

14. Solberg, V.S. ILP Resources. Available online: https://drive.google.com/drive/u/0/folders/18tkOfY08Sc6e0ATPvx7M7cv_oJJ8nKwp (accessed on 11 February 2019).

15. Solberg, V.S.; Phelps, L.A.; Haakenson, K.A.; Durham, J.F.; Timmons, J. The Nature and Use of Individualized Learning Plans as a Promising Career Intervention Strategy. J. Career Dev. 2011, 39, 500-514. [CrossRef] 
16. Solberg, V.S.; Howard, K.; Gresham, S.; Carter, E. Quality Learning Experiences, Self-Determination, and Academic Success: A Path Analytic Study Among Youth With Disabilities. Career Dev. Transit. Except. Individ. 2012, 35, 85-96. [CrossRef]

17. Solberg, V.S.; Gusavac, N.; Hamann, T.; Felch, J.; Johnson, J.; Lamborn, S.; Torres, J. The Adaptive Success Identity Plan (ASIP): A career intervention for college students [Monograph]. Career Dev. Q. 1998, 47, 48-95. [CrossRef]

18. Solberg, V.; Martin, J.; Larson, M.; Nichols, K.; Booth, H.; Lillis, J.; Costa, L. Promoting Quality Individualized Learning Plans Throughout the Lifespan: A Revised and Updated ILP How To Guide 2.0. Institute for Educational Leadership. 2018. Available online: http:/ / www.ncwd-youth.info/wp-content/uploads/2018/03/Promoting-Quality-ILPs-Throughout-the-Lifespan-WEB. pdf (accessed on 1 April 2018).

19. Solberg, V.S.H.; Park, C.M.; Marsay, G. Designing Quality Programs that Promote Hope, Purpose and Future Readiness Among High Need, High Risk Youth: Recommendations for Shifting Perspective and Practice. J. Career Assess. 2020, 29, 183-204. [CrossRef]

20. Solberg, V.S.; Wills, J.; Redmond, K.; Skaff, L. Use of Individualized Learning Plans: A Promising Practice for Driving College and Career Readiness Efforts. Findings and Recommendations from a Multi-Method, Multi-Study Effort. National Collaborative on Workforce and Disability for Youth, Institute for Educational Leadership. 2014. Available online: http:/ /www.ncwd-youth.info/ use-of-individualized-learning-plans (accessed on 28 December 2014).

21. Advocates for Youth. Youth and the State of the World. Global Roundtable Working Group on Youth. Available online: https: //www.advocatesforyouth.org/wp-content/uploads/storage//advfy/documents/fsstateworld.pdf (accessed on 3 March 2021).

22. International Labor Organization. What Does NEETs Mean and Why Is the Concept So Easily Misinterpreted? International Labor Organization Youth Employment Program, Work4Youth, Technical Brief 1. 2015. Available online: https://www.ilo.org/ wcmsp5/groups/public/---dgreports/---dcomm/documents/publication/wcms_343153.pdf (accessed on 15 February 2015).

23. Massachusetts Department of Elementary and Secondary Education. Graduation Rates. Available online: https://www.doe. mass.edu/infoservices/reports/gradrates/ (accessed on 14 June 2021).

24. Munoz, A.P.; Kim, M.; Chang, M.; Jackson, R.O.; Hamilton, D.; Darity, W.A., Jr. The Color of Wealth in Boston. Federal Reserve Bank of Boston, A Joint Publication of Duke University, The New School, and the Federal Reserve Bank of Boston. 2015. Available online: https:/ / www.bostonfed.org/publications/one-time-pubs/color-of-wealth.aspx (accessed on 10 September 2019).

25. Stroh, D. Systems Thinking for Social Change: A Practical Guide to Solving Complex Problems, Avoiding Unintended Consequences and Achieving Lasting Results; Chelsea Green Publishing: Hartford, VT, USA, 2015.

26. Barabasi, A.-L. Linked: How Everything Is Connected to Everything Else and What It Means; Plume: New York, NY, USA, 2002.

27. Evans, D. The Internet of Things: How the Next Evolution of the Internet Is Changing Everything. Cisco Internet Business Solutions Group. 2011. Available online: https://www.cisco.com/c/dam/en_us/about/ac79/docs/innov/IoT_IBSG_0411FINAL. pdf (accessed on 1 May 2021).

28. Lazer, D.; Pentland, A.; Adamic, L.; Aral, S.; Barabasi, A.-L.; Brewer, D.; Christakis, N.; Contractor, N.; Fowler, J.; Gutmann, M.; et al. Computational social science. Science 2009, 323, 721-723. [CrossRef]

29. Pentland, A. Social Physics: How Good Ideas Spread-The Lessons from a New Science; Penguin Press: Westminster, London, England, 2014.

30. Watts, D.J. A twenty-first century science. Nature 2007, 445, 489. [CrossRef]

31. Meadows, D.L.; Behrens, W.W., III; Meadows, D.M.; Naill, R.F.; Randers, J.; Zahn, E.K.O. Dynamics of Growth in a Finite World; Wright-Allen Press: Cambridge, MA, USA, 1974.

32. United Nations. Goals 8: Promote Sustained, Inclusive and Sustainable Economic Growth, Full and Productive Employment and Decent Work for All. Department of Economic and Social Affairs, Sustainable Development. Available online: https: //sdgs.un.org/goals/goal8 (accessed on 28 January 2020).

33. United Nations. The Sustainable Development Goals Report. United Nations. 2017. Available online: https://unstats.un.org/ sdgs / files / report/2017/thesustainabledevelopmentgoalsreport2017.pdf (accessed on 17 January 2018).

34. Chen, Z.; Solberg, V.S.H. Pathways From Caring and Engaging Adults to Youth Vocational Identity: The Mediational Roles of Career Search Self-Efficacy and Goal Capacity. Youth Soc. 2015, 50, 780-800. [CrossRef]

35. Sultana, R.G. Career guidance in multicultural societies: Identity, alterity, epiphanies and pitfalls. Br. J. Guid. Couns. 2017, 45, 451-462. [CrossRef]

36. Bhatia, S.; Priya, K.R. Decolonizing culture: Euro-American psychology and the shaping of neoliberal selves in India. Theory Psychol. 2018, 28, 645-668. [CrossRef]

37. Katz, L.F.; Krueger, A.B. The Rise and Nature of Alternative Work Arrangements in the United States, 1995-2015. Ind. Labor Relat. Rev. 2018, 72, 382-416. [CrossRef]

38. Henwood, D. No It's Not a Gig Economy. Jacobin Magazine. 2018. Available online: https://www.jacobinmag.com/2018/06/ gig-economy-debunked-precarity-contingency (accessed on 1 December 2018).

39. Blustein, D.L.; Erby, W.; Meerkins, T.; Soldz, I.; Ezema, G.N. A Critical Exploration of Assumptions Underlying STEM Career Development. J. Career Dev. 2020. [CrossRef]

40. Cappelli, P.; Tavis, A. HR Goes Agile. Spotlight Series The New Rules of Talent Management. Harvard Business Review. March-April 2018 Issue. Available online: https:/ hbr.org/2018/03/hr-goes-agile (accessed on 1 May 2018).

41. EdVestors. Career Pathways. Available online: https://www.edvestors.org/career-pathways (accessed on 14 June 2021). 
42. Perry, J.; President, M.; Harmon, J.; Calhoun-Butts, C.; Riley, S.; Wallace, E.; Barto, L.; O’Janpa, L.; Myers, J.; Trepal, T.; et al. Making My Future Work: A College and Career Readiness Program. US Department of Education Institute of Education Sciences. 2014. Available online: https:/ / cehs.csuohio.edu/sites/csuohio.edu.cehs/files/MMFW\%20Curriculum\%20Manual\%202014.pdf (accessed on 8 June 2015).

43. Perry, J.C.; Wallace, E.W.; McCormick, M.P. Making My Future Work: Evaluation of a New College and Career Readiness Curriculum. Youth Soc. 2016, 50, 841-866. [CrossRef]

44. Yoder, N.; Atwell, M.N.; Godek, D.; Dusenbury, L.; Bridgeland, J.M.; Weissberg, R. Preparing Youth for the Workforce of Tomorrow: Cultivating the Social and Emotional Skills Employers Demand. CASEL, SEL for Workforce Development, Collaborating State Initiatives. 2020. Available online: https://casel.org/wp-content/uploads/2020/06/Preparing-Youth-for-the-Workforce-ofTomorrow-Final.pdf (accessed on 8 July 2020).

45. Nearpod. Nearpod: Make Every Lesson Interactive [Software]. Available online: https:/ / nearpod.com/ (accessed on 28 July 2021).

46. National Center for Rural Education Research Networks. National Center for Rural Education Research Network (NCRERN). Harvard University Center for Education Policy Research. Available online: https:/ / cepr.harvard.edu/rural (accessed on 15 July 2021 ).

47. Flood, J.; Minkler, M.; Lavery, S.H.; Estrada, J.; Falbe, J. The Collective Impact Model and Its Potential for Health Promotion: Overview and Case Study of a Healthy Retail Initiative in San Francisco. Health Educ. Behav. 2015, 42, 654-668. [CrossRef] [PubMed]

48. Massachusetts Department of Elementary and Secondary Education (MA DESE; 2020). My Career and Academic Plan (MyCAP): College and Career Advising Program (CCA). Available online: https://www.doe.mass.edu/ccte/ccr/mycap/ (accessed on 1 February 2021).

49. Arcadia School District. College \& Career Readiness: Academic \& Career Planning. Available online: https://www.arcadia.k12. wi.us/academics/readiness (accessed on 3 March 2021).

50. Boston Public Schools. Defining College, Career \& Life Readiness. 2020. Available online: https: / www.bostonpublicschools. org/Page/7047 (accessed on 19 April 2021).

51. Boston Public Schools Equity Design Team. MyCAP Lesson Design Consideration. BPS Equity Design Team. 2021. Available online: https://docs.google.com/document/d/1588fxTVjDagG_3xEj7RMwyNq9oVrhhCq/edit (accessed on 1 July 2021).

52. Morgan-Trimmer, S.; Wood, F. Ethnographic methods for process evaluations of complex health behaviour interventions. Trials 2016, 17, 232. [CrossRef] [PubMed]

53. Bansal, S.; Mahendiratta, S.; Kumar, S.; Sarma, P.; Prakash, A.; Medhi, B. Collaborative research in modern era: Need and challenges. Indian, J. Pharmacol. 2019, 51, 137-139. [CrossRef]

54. Mills, K. Why a Collaborative Research Culture Is Needed to Address the COVID-19 Challenge. Analysis and Commentary. Queen's University Belfast. 2021. Available online: https:/ / www.qub.ac.uk/coronavirus/analysis-commentary/collaborativeresearch-culture-needed-to-address-covid-19/ (accessed on 10 August 2021).

55. National Research Council. The Geological Record of Ecological Dynamics: Understanding the Biotic Effects of Future Environmental Change; The National Academies Press: Washington, DC, USA, 2005. [CrossRef]

56. Braun, V.; Clarke, V. Using thematic analysis in psychology. Qual. Res. Psychol. 2006, 3, 77-101. [CrossRef]

57. Patton, M.Q. Enhancing the quality and credibility of qualitative analysis. Heal. Serv. Res. 1999, 34, 1189-1208.

58. Taussig, M. I Swear I Saw This. Drawings in Fieldwork Notebooks, Namely My Own; The University of Chicago Press: Chicago, IL, USA, 2011.

59. Richardson, L.; St. Pierre, E. Writing: A method of Inquiry. In The Sage Handbook of Qualitative Research; Denzin, N., Lincoln, Y., Eds.; Sage: Thousand Oaks, CA, USA, 2005; pp. 959-978.

60. Kennedy, L.A.; MacNeela, P. Adolescent acculturation experiences: A meta-ethnography of qualitative research. Int. J. Intercult. Relations 2014, 40, 126-140. [CrossRef]

61. Burroughs, J.M. No Uniform Culture: Patterns of Collaborative Research in the Humanities. Portal Libr. Acad. 2017, 17, 507-527. [CrossRef] 